\title{
Inclusão na educação superior: formação e experiência docente
}

\author{
Inclusion in higher education: training and teaching experience
}

\author{
Elaine Gomes Matheus Furlan ${ }^{1}$ \\ ${ }^{1}$ Universidade Federal de São Carlos | Departamento de Ciências da Natureza, Matemática e \\ Educação | Araras | SP | Brasil. Contato: elainefurlan.ufscar@gmail.com. ORCID: \\ https://orcid.org/0000-0002-5413-7964
}

\author{
Paulo Cézar de Faria ${ }^{2}$ \\ ${ }^{2}$ Universidade Federal de São Carlos | Departamento de Ciências da Natureza, Matemática e \\ Educação | Araras | SP | Brasil. Contato: paulofaria@ ufscar.br. ORCID: \\ https://orcid.org/0000-0002-1401-5225
}

\author{
Daniele Lozano ${ }^{3}$ \\ ${ }^{3}$ Universidade Federal de São Carlos | Departamento de Ciências da Natureza, Matemática e \\ Educação | Araras | SP | Brasil. Contato: lz.dani@ufscar.br. ORCID: https://orcid.org/0000- \\ $\underline{0002-2379-5403}$
}

Fernanda Vilhena Mafra Bazon ${ }^{4}$

${ }^{4}$ Universidade Federal de São Carlos | Departamento de Ciências da Natureza, Matemática e Educação | Araras | SP | Brasil. Contato: fernandavmb@ufscar.br. ORCID:

http://orcid.org/0000-0002-2949-2219

\section{Claudia Gomes 5}

${ }^{5}$ Universidade Federal de Alfenas | Instituto de Ciências Humanas e Letras | Alfenas | MG |

Brasil. Contato: cg.unifal@ gmail.com. ORCID: https://orcid.org/0000-0001-5951-8937

Resumo: A investigação delimitou como objeto de estudo a formação e a experiência docente com alunos que possuem deficiência e/ou Necessidades Educacionais Especiais, buscando o entendimento que docentes universitários possuem acerca do processo inclusivo, bem como as práticas inclusivas realizadas por eles em cursos de licenciatura. A abordagem metodológica qualitativa, permitiu utilizar entrevistas semiestruturadas com docentes de duas instituições públicas federais localizadas nos estados de São Paulo e Minas Gerais. A análise de dados permitiu identificar que as ações pedagógicas desenvolvidas pelos sujeitos devem respeitar os ideais inclusivos, mas que as barreiras atitudinais, físicas e o déficit na formação docente são questões que podem levar ao processo de inclusão marginal, transformando as escolas em ambientes perversos, não possibilitando, as vezes, a participação efetiva dos alunos no processo de ensino-aprendizagem. É preciso avançar no entendimento de que o aluno com deficiência e/ou Necessidades Educacionais Especiais requer responsabilidade de todos, portanto, as instituições precisam apoiar o corpo docente no processo de formação continuada para que seja efetiva a formação inicial dos futuros professores que atuarão na educação básica inclusiva. As análises revelaram ainda a preocupação com a adesão em cursos voltados para os formadores sobre a educação inclusiva, além da necessidade de informações que possam orientar o professor caso ele tenha em sala de aula um aluno com deficiência e/ou Necessidades Educacionais Especiais. O estudo evidenciou que o ideal da educação inclusiva é consoante com a busca de igualdade de direitos, tanto no que se refere à escolarização quanto à participação social.

Palavras-chave: Inclusão. Necessidades educacionais especiais. Formação de professores. Práticas pedagógicas.

Abstract: The investigation delimited the training and teaching experience of students with disabilities and / or Special Educational Needs as the object of study, seeking the understanding that university teachers have about the inclusive process, as well as the inclusive practices performed by them in undergraduate courses. The qualitative methodological approach allowed to use semi-structured interviews with professors from two federal public institutions located in the states of São Paulo and Minas Gerais. The data analysis allowed to identify that the pedagogical actions developed by the subjects must respect 
the inclusive ideals, but that the attitudinal, physical barriers and the deficit in teacher education are issues that can lead to the process of marginal inclusion, transforming schools in perverse environments, sometimes not allowing the effective participation of students in the teaching-learning process. It is necessary to advance in the understanding that students with disabilities and Special Educational Needs require everyone's responsibility, therefore, institutions need to support the teaching staff in the process of continuing education so that the initial training of future teachers who will work in education is effective. inclusive basic. The analyzes also revealed the concern with adherence to courses aimed at trainers on inclusive education, in addition to the need for information that can guide the teacher if he has a student with a disability and / or Special Educational Needs in the classroom. The study showed that the ideal of inclusive education is consistent with the search for equal rights, both regarding schooling and social participation.

Keywords: Inclusion. Special educational needs. Teacher training. Pedagogical practices.

Palavras-chave: Inclusão. Necessidades educacionais especiais. Formação de professores. Práticas pedagógicas.

- Recebido em: 26 de abril de 2018 - Aprovado em: 1 de junho de 2020

DOI: http://dx.doi.org/10.1590/S1414-40772020000200010

Este é um artigo publicado em acesso aberto sob uma licença Creative Commons https://creativecommons.org/licenses/by-nc/4.0/

\section{Introdução}

A questão da educação inclusiva é fenômeno analisado mundialmente e as ações em favor da inclusão ${ }^{1}$ são discutidas sob o ponto de vista político, cultural, social e pedagógico. Neste sentido, concordamos com Bueno (2008) que a Inclusão Escolar busca incorporar ao sistema regular de ensino os alunos que tradicionalmente foram excluídos da escola, já a Educação Inclusiva "refere-se a um objetivo político a ser alcançado" (p. 49).

O estudo desenvolvido por Laplane (2006) analisou as condições de implementação de políticas de educação inclusiva no Brasil e no Reino Unido. A autora constatou que a execução dessas políticas é pontuada por um conjunto de leis e documentos oficiais que buscam especificar as ações inclusivas. No entanto, observa que, nos dois países, as práticas inclusivas encontram obstáculos tanto nos conflitos e tensões gerados pelas condições sociais gerais, como nas características dos sistemas educacionais. Outra constatação foi apontada por Mura e Zurru (2016) com relação ao sistema de inclusão escolar na Itália, destacando que embora a inclusão escolar tenha sido estabelecida e estruturada institucionalmente na escola pública daquele país,

\footnotetext{
${ }^{1}$ O termo "inclusão" no Brasil passa a ser usado amplamente a partir da segunda tradução da Declaração de Salamanca (UNESCO) feita pela Coordenadoria Nacional para Integração da Pessoa Portadora de Deficiência (CORDE) em 1997.
} 
ainda é evidente a necessidade de melhoria da qualidade dos processos inclusivos, pois esta "é uma realidade inacabada, e que isso requer a contínua avaliação das dinâmicas e fenômenos que caracterizam esse processo.” (MURA; ZURRU, 2016, p. 365).

Ao analisar o histórico da educação especial no Brasil, Mendes (2010) destaca que parte do alunado ${ }^{2}$ atendido pelo processo inclusivo, tem tido acesso a algum tipo de escola, contudo, eles não estão necessariamente recebendo uma educação apropriada, seja por falta de profissionais qualificados ou mesmo pela falta de recursos. O Brasil vem seguindo a tendência mundial de criar sistemas educacionais inclusivos e pretensamente menos restritivos à participação de pessoas com deficiência e/ou NEE (BRASIL, 2011). A estas pessoas têm sido assegurado o direito de frequentar a escola ao lado das outras crianças e jovens da sua geração, em vez de permanecerem segregadas em escolas, classes ou instituições especiais, como historicamente se verificou na educação brasileira. Entretanto, Bezerra (2017, p. 475) nos esclarece que a inclusão ainda "revela-se seletiva, classificatória e estigmatizante, contribuindo para a reprodução da ordem estabelecida e para a legitimação das desigualdades entre os agentes escolares, o que constitui o processo de exclusão por dentro do sistema escolar".

Nesse sentido, há razões para supor que este é um problema que afeta a proposta de inclusão escolar em nosso país e pode ter sido originado a partir de muitos descompassos em torno deste tema e também da tendência neoliberal impregnada nas políticas educacionais a partir da década de 1990 como discutido por Arce (2001) e Libâneo, Oliveira e Toschi (2012). Bezerra (2017) ainda chama a atenção para o seguinte aspecto: "conhecer esses processos de reprodução e segregação escolar por dentro do sistema de ensino, abre-nos a possibilidade de enfrentar, doravante, tais mecanismos e suas ideologias subjacentes com maiores chances de êxito" (p. 495). Sendo assim, e conforme discutido por Martins (2002) e Patto (2008), faz-se necessário o conhecimento dos processos de reprodução, segregação escolar e inclusão precária, especialmente no momento em que se constata o ingresso de uma quantidade cada vez maior de estudantes com deficiências e/ou NEE tanto na educação básica quanto na educação superior, no Brasil.

Goessler (2014) constata um acréscimo na porcentagem de matrículas referente a essa população, na educação superior. No ano 2012 a autora observa que do total de matriculas

\footnotetext{
${ }^{2}$ Entendemos que o processo inclusivo é mais amplo do que o atendimento aos alunos que se configuram como público alvo da educação especial, isto é aqueles que apresentam deficiência, transtornos globais de desenvolvimento ou altas habilidades. Compreendemos que o processo inclusivo deve ser destinado à estes alunos sim, mas também àqueles que apresentem uma Necessidade Educacional Especial (NEE) e portanto fazem parte de grupos que historicamente ficaram segregados do ensino regular.
} 
realizadas na educação superior, $0,42 \%$ foram efetuadas no ensino público e $0,34 \%$ foram efetuadas no ensino privado. Pieczkowski (2016) constatou que, no ano 2013 , apenas $0,41 \%$ do total de estudantes matriculados na educação superior apresentam NEE. O percentual de estudantes com NEE é baixo, quando comparado total de estudantes matriculados na educação superior. Entretanto, Pieczkowski (2016) constatou que em uma década (de 2003 a 2013) ocorreu um aumento significativo $(590,78 \%)$ na quantidade de estudantes com deficiência matriculados na educação superior.

Com o ingresso cada vez maior de alunos com NEE na educação superior se faz necessário o aprofundamento da reflexão sobre a educação inclusiva também neste âmbito educacional. Diante do exposto podemos levantar o seguinte questionamento: qual é a formação e a experiência dos docentes universitários com alunos com deficiência e/ou NEE? E ainda, em que medida o currículo e as práticas pedagógicas adotadas por estes docentes são condizentes com as necessidades apresentadas por estes alunos?

A partir destas considerações, destacamos o entendimento de que os cursos de licenciatura devem garantir discussões que permeiam a educação inclusiva e a diversidade do alunado. Nesse sentido se faz necessário que os docentes universitários pensem e atuem com o propósito de fortalecer a formação inicial, de modo que os futuros professores estejam preparados para atender alunos com necessidades educacionais especiais em sua atuação profissional.

Tendo em vista o compromisso da universidade com a produção e a divulgação do conhecimento científico, com base no contexto social, realizamos uma investigação com o objetivo de: analisar a formação e as experiências dos docentes que atuam em cursos de licenciatura no que tange à diversidade e aos pressupostos inclusivos.

A escolha das instituições participantes desta investigação se deu em decorrência do vínculo institucional dos pesquisadores. Contudo, cabe ressaltar que o histórico dos cursos de licenciatura envolvidos, tanto na Universidade Federal de São Carlos - UFSCar (campus Araras-SP) quanto na Universidade Federal de Alfenas - UNIFAL (Alfenas-MG), se assemelham, pois ambos foram criados pelo REUNI (Programa de Apoio a Planos de Reestruturação e Expansão das Universidades Federais) e possuem características de estrutura e distribuição de recursos humanos que favoreceram a discussão proposta pelo presente estudo.

Podemos ainda destacar que o conhecimento gerado a partir do desenvolvimento deste estudo foi considerado, pelos pesquisadores, como central para a estruturação do conhecimento presente nas atividades acadêmicas realizadas pelos docentes, em diferentes cursos de 
graduação, no que concerne ao desenvolvimento de práticas que produzem questões concretas e exigem respostas relativas à problemática da inclusão e das NEE.

Desta forma, os resultados da presente investigação além de contribuir para a discussão na área, focalizando os formadores, fortalecem o processo de formação inicial docente; notadamente a partir de possíveis ações de intervenção que podem ser ocasionadas pelo estudo realizado.

\section{A questão da inclusão/exclusão nos meios educacionais}

Alguns dados, como por exemplo aqueles disponíveis nas Sinopses Estatísticas do Censo da Educação Superior do INEP (Instituto Nacional de Estudos e Pesquisas Educacionais Anísio Teixeira), nos mostram que o acesso à educação básica regular está sendo democratizado, entretanto este acesso garante a efetiva inclusão? A partir desta indagação surge outra: os professores que atuam neste nível educacional estão sendo formados para atuar de maneira a incluir os alunos com deficiência e/ou NEE no processo de ensino-aprendizagem?

Se os dados da educação básica mostram um aumento expressivo nestas matrículas, as sinopses estatísticas referentes ao ensino superior entre os anos de 2004 e 2015 não apresentam qualquer referência ao ingresso de alunos com deficiência e/ou NEE nos cursos de graduação. Sabemos, por observação em nosso cotidiano e por dados de estudos, que a inclusão no ensino superior vem ocorrendo; entretanto não conseguimos estabelecer em que proporção e se o acesso está ou não sendo ampliado. Desta forma, torna-se ainda mais relevante focarmos 3 nossa atenção tanto nas condições de inclusão neste nível educacional, quanto na formação de professores para atuar em uma educação básica, cada vez mais repleta de alunos com NEE, sem que suas ações levem à inclusão marginal ou precária, como discutido por Martins (2002), Amaral (2002) e Patto (2008).

Neste sentido, muitas discussões a respeito da educação inclusiva estão associadas ao antagonismo inclusão/exclusão. Por um lado, a inclusão escolar é vista como possibilidade essencial para a transformação da sociedade, na medida em que a inclusão pressupõe o respeito às diferenças e compreende as condições favoráveis e necessárias para receber, manter e promover com plenas competências as pessoas com necessidades educacionais especiais. Mas, por outro lado se observa que a prática pedagógica escolar apresenta dificuldades acerca de entendimentos, aceitação e organização pedagógica para a finalidade da inclusão.

\footnotetext{
${ }^{3}$ Apesar destes dados não serem apresentados nas sinopses eles podem ser consultados via microdados e análise no software SPSS o que limita o acesso da população e da academia às informações.
} 
O estudo desenvolvido por Falkenbach e colaboradores (2007, p. 38) apontou que a inclusão "pode constituir-se em uma ação extremamente complexa aos professores e à comunidade escolar, uma vez que a ação pedagógica tem buscado a universalização e uniformização do conhecimento". Tal ação pedagógica provoca o distanciamento entre o projeto pedagógico e a realidade vivenciada pelos membros da comunidade escolar e a consequente falta de articulação política e comunitária na ação coletiva desta comunidade. E ainda Falkenbach e colaboradores (2007, p. 38) alertam para o fato de que este "aspecto pode deixar o professor em situação de isolamento e sem apoio diante dessa nova realidade, dificultando sua atuação pedagógica com os alunos".

Por outro lado, na escola ainda se observa que "a luta pela efetivação de direitos esbarra na identificação das diferenças ainda como algo extraordinário e não como - de fato constitutivas de nossa população.” (KASSAR, 2012, p. 845). A ação pedagógica dos professores está eivada pela identificação das diferenças. Assim, esta ação não pode estar respaldada no senso comum e no empirismo; sob pena de dificultar a aceitação das diferenças entre as pessoas e o desrespeito à individualidade. Nesse sentido a realização de ação educativa inclusiva se apresenta como um desafio na medida em que ela exige ambiente escolar novo, criativo e organizado de modo a respeitar as características individuais.

A efetivação do processo inclusivo necessita em grande parte de uma formação de professores que esteja atenta para as condições de escolarização de alunos com NEE. É preciso que os cursos superiores, em especial os de licenciatura tragam discussões sobre a aprendizagem destes alunos, de forma a favorecer o processo inclusivo pela atuação dos futuros professores.

\section{A inclusão na educação superior}

Ao desenvolver uma investigação a respeito da educação inclusiva no ensino superior Ferrari e Sekkel (2007) identificaram três níveis de desafios a serem enfrentados. O primeiro se refere à tomada de posição das instituições sobre os objetivos e a elegibilidade dos alunos para seus cursos. O segundo se reporta à necessidade de formação pedagógica dos professores do ensino superior para a educação inclusiva. O terceiro se refere à necessidade de uma prática educativa que propicie a participação de alunos e professores no reconhecimento das diferenças e na criação de estratégias para a superação das dificuldades que surgirem.

Com relação ao primeiro desafio nós podemos destacar que a questão da inclusão se remete ao nível da responsabilidade institucional; a qual deve criar as condições para o processo 
da inclusão se torne adequado e efetivo. Nesse sentido a educação inclusiva não deve estar com o foco apenas nas ações afirmativas que visam a inclusão social das camadas mais pobres da população por meio de cotas para estudantes. As ações de inclusão devem estar voltadas para a questão do preconceito, que pode afetar os estudantes cotistas, mas também para outros alvos de preconceito tais como os estudantes que apresentam necessidades educacionais especiais na educação superior. Nesse sentido vale destacar o alerta apresentado por Ferrari e Sekkel (2007, p. 642) "Se entendermos o preconceito como manifestação individual cuja origem é social, podemos antever sua presença nas relações em sala de aula".

Com relação ao segundo desafio apontamos o fato de que a formação pedagógica dos professores do ensino superior para a educação inclusiva não deve ser uma ação isolada, centrada apenas no professor. Antes de tudo ela deve ser uma ação institucional que busca envolver toda a comunidade acadêmica nas discussões sobre as práticas educacionais voltadas para a inclusão.

Por fim, a necessidade de uma prática educativa que propicie a participação de alunos e professores no reconhecimento das diferenças requer um trabalho de reflexão e conscientização a respeito das atitudes frente às diferenças. Nesse sentido,

Tal trabalho deve ser iniciado na formação do professor, o que reforça a necessidade de formação pedagógica do docente do ensino superior que contemple a reflexão. Essa reflexão revela-se tão importante quanto o domínio de conteúdos específicos das áreas de conhecimento, pois ambos os fatores podem ser decisivos para a efetividade das ações educativas (FERRARI; SEKKEL, 2007, p. 642).

Notamos que a preocupação com a formação docente não é exclusiva ao nosso país, sendo discutida em diversas esferas tanto em outros países da América Latina, quanto da Europa, onde também encontramos grandes desafios para o processo de formação. Ao pensar na construção de uma educação democrática, como proposta por Bueno (2008), torna-se essencial que a inclusão seja eficiente e possa favorecer a equiparação de oportunidades.

Vygotski (1997) já defendia no início do século XX que as oportunidades de escolarização e desenvolvimento devem ser garantia de todos os indivíduos, apresentem eles uma deficiência ou não. Em sua teoria, especialmente no que se refere aos fundamentos da defectologia, o autor aponta para o papel revolucionário da educação na vida das pessoas e para a necessidade de superação da esfera biológica pela esfera cultural, com os mecanismos de compensação.

A partir destas considerações temos que reconhecer a extrema importância do trabalho docente no processo de escolarização de todos os indivíduos, sendo essencial que, assim como 
proposto por Saviani (2008), o professor, a partir da análise de sua realidade, reconheça a posição que ocupa no grupo social, para assim poder atuar de forma a romper com a falsa noção de igualdade de oportunidades e a divisão social do trabalho.

A formação de professores que possam atender à diversidade do alunado se torna essencial para a concretização do ideal inclusivo. Pesquisas, como as de Prietro (2003) e Michels (2008), apontam para a necessidade de discutir o processo inclusivo na formação inicial e continuada, de forma a desenvolver o respeito e reconhecimento da diversidade do alunado em seus aspectos sociais, culturais e físicos, buscando sempre o combate a toda forma de discriminação e barreira atitudinal.

\section{Procedimentos de obtenção e análise de dados}

O presente estudo apresenta características de uma investigação de natureza qualitativa, na perspectiva apontada por Gonzalez Rey (2002), já que temos como base a ideia de que cada ambiente é constituído por características e necessidades próprias. Focamos nossa atenção no conhecimento da realidade local apresentado por docentes, estando eles inseridos em um meio cultural, histórico e social particular. Nesse contexto, a pesquisa qualitativa favoreceu a expressão dos participantes o que possibilitou conhecer as percepções de docentes sobre a inclusão na educação superior.

Efetuamos a coleta dos dados por meio de procedimentos vinculados à entrevista semiestruturada, pois conforme Lüdke e André (1986) a entrevista semiestruturada possui um esquema básico que não é aplicado rigidamente, permitindo que o entrevistador faça adaptações quando necessário. Desse modo o roteiro da entrevista foi flexível e permitiu que o pesquisador pudesse verificar, no discurso do sujeito, quais itens do roteiro estavam sendo contemplados; podendo assim fazer o questionamento de outros itens que ainda não haviam sido contemplados. Esse aspecto possibilitou uma melhor descrição das falas e sua análise.

Conforme a necessidade da elegibilidade dos contextos e dos participantes em estudos qualitativos a investigação foi realizada na Universidade Federal de São Carlos - UFSCar (campus Araras-SP) e na Universidade Federal de Alfenas - UNIFAL (Alfenas-MG). A amostra, com 18 informantes ${ }^{4}$ foi escolhida de forma aleatória, tomando como critérios de inclusão: ser docente efetivo de um dos cursos de licenciatura nas Instituições de Ensino Superior investigadas e ter ministrado disciplina em pelo menos um dos cursos de licenciatura

4 Os dados discutidos neste artigo referem-se à segunda etapa de uma pesquisa mais ampla. 
destas Instituições nos últimos seis meses. Foram considerados participantes professores de distintas disciplinas, contemplando tanto a área pedagógica, quanto a área específica; totalizando, na etapa de entrevistas, 12 docentes da UFSCar e 6 docentes da UNIFAL. Os dados fornecidos pelos participantes (conforme as diferentes formas de coleta) foram obtidos diretamente dos sujeitos, localizados no seu ambiente de trabalho.

\section{Análise e discussão dos resultados}

O procedimento de a análise dos dados obtidos a partir das entrevistas realizadas com os docentes conduziu à organização do seguinte eixo de interpretação: Formação e experiência docente com alunos com deficiência e/ou NEE.

Para efetuar a análise e interpretação deste eixo, foi necessária a divisão do mesmo em cinco núcleos: 1) Experiências com alunos com deficiência e/ou NEE; 2) Incentivo ou iniciativas da universidade para a formação dos formadores, voltada para a educação inclusiva; 3) Sugestões para melhoria da formação dos formadores em relação à inclusão; 4) Formação voltada para a educação inclusiva durante a trajetória acadêmica; 5) Interesse em que a instituição oportunize espaços para a formação na área de educação inclusiva para os formadores.

\subsection{Experiências com alunos com deficiência e/ou NEE}

Entendemos que para a construção de uma escola e sociedade democráticas, a formação e a prática cotidiana dos professores precisam se voltar para o entendimento da realidade concreta e das desigualdades inerentes a ela de forma crítica. Para isso buscamos, no caso de alunos com deficiência e/ou NEE, atuar de forma a compensar as limitações decorrentes, por exemplo, por uma deficiência ou pelas deficiências secundárias, portanto sociais, que surgem quando um indivíduo foge ao padrão de normalidade estabelecido (VYGOTSKI, 1997; AMARAL, 2002). Neste sentido, torna-se necessário compreender as experiências dos docentes formadores e como os mesmos refletem sobre estes aspectos na formação dos futuros professores, ou seja, como a formação e prática dos professores são (re)pensadas, como eles analisam as situações cotidianas e como ensinam futuros professores a refletirem sobre as questões da educação inclusiva, de fato.

No conjunto dos dados, quatro docentes tiveram, inclusive, dificuldade de identificar as experiências, dentre eles destacamos a resposta de P10: 
A dificuldade vai até em você delimitar o que é uma necessidade especial, então, por exemplo aqui na UFSCar nós tivemos uma aluna que tinha esclerose múltipla, não sei se isso é característico por uma necessidade especial, que em épocas de crise ela não anda, então tem toda uma necessidade também, principalmente nas atividades de campo, você tem que saber lidar com isso também, então, a formação da gente é tão falha, que a gente não consegue nem delimitar, o que é uma necessidade especial (P10).

Portanto, as dificuldades estão desde a identificação, a linguagem, enfim o modo como se referem e lidam com seus alunos, futuros professores, que também precisam estar preparados para o processo inclusivo. Neste sentido, verificar as experiências são mecanismos importantes para desvendar as ações, práticas, o que está explícito e implícito, aspectos tácitos que os professores apontam e precisam ser discutidos para que o processo inclusivo se torne efetivo.

A Resolução CNE n. 02/2001 (BRASIL, 2001) aponta para a necessidade de que os egressos dos cursos de licenciatura sejam capazes de identificar alunos com deficiência e/ou NEE e ensiná-los dentro das escolas comuns. Como isso é possível se os próprios formadores não conseguem identificar e se sentem despreparados para lidar com essas questões nos cursos de licenciatura?

Alguns participantes evidenciaram experiências anteriores ao longo de suas carreiras, demonstrando a diversidade também no ensino superior e como lidaram com estas questões. A seguir alguns comentários:

[...] Foi quando eu era professora substituta na UNICAMP, em 2012 antes de me efetivar aqui na UFSCar, foi na disciplina de introdução a ecologia, que nós tivemos um aluno autista. [...] Essa disciplina envolvia idas á campo, idas a Ubatuba, ao Cerrado de Itirapina, Serra do Japi, então a gente tinha medo. E, assim, nós como professores e eles até muito mais velhos, muito mais experientes do que eu, também não sabiam como lidar com isso, e nós pedimos permissão para pró-reitoria de graduação, na época e a gente pediu para que os pais dessa pessoa acompanhasse todas as excursões, porque a gente realmente não sabia como lidar, tanto fisicamente quanto emocionalmente com a pessoa (P10).

[...] a deficiência dele não estava ligada ao raciocínio, não era mental. Ele tinha dificuldade para escrever, segurar a caneta, fazer as anotações de aula. [...] Assim, no começo da graduação, eu lembro que a mãe e o pai dele iam com ele fazer as anotações, mas é porque fazia pouco tempo que ele tinha sofrido o acidente, aí ao longo da graduação ele foi conseguindo escrever. [...] Então, por exemplo, os alunos não podem entrar de carro no prédio, mas ele podia, os pais dele entravam para pegar a cadeira de rodas, colocavam, os pais dele transitavam livremente na universidade, coisa que para os outros pais dos outros alunos não era possível. Mas, pedagogicamente, não, até porque eu acho que ele não precisava. (P15).

Essas questões afirmam a identificação, mas também a necessidade e importância que os docentes revelam a respeito do apoio e envolvimento da família para aspectos considerados novos, desconhecidos e desafiadores, entre outros aspectos. Nesse sentido, os docentes destacam com frequência a necessidade de preparo, além do contato com a família, ou seja, de formação profissional para conseguir identificar e conduzir as situações. 
Olha eu não tive preparação, nenhum treinamento, não conversei com nenhum profissional do campus a respeito disso. [...] Eu acho que sim, eu acho bastante importante sim essa formação (P13).

Então, é interessante, mas eu nunca tive. [...] Foi por conta própria, acho que infelizmente essas coisas têm acontecido dessa forma, a gente não é preparado para trabalhar com essas questões, a gente tem que se preparar, tem que buscar informação e tal, porque é aquela história, você pode falar "ai, não fui formado para isso", mas a questão é: o aluno está aqui e ele tem todo direito a receber uma educação adequada, não posso dizer que não fui formado para isso (P14).

Estas são situações vivenciadas ao longo da carreira dos docentes que demonstram que mesmo sem o preparo para lidar com questões vinculadas à educação inclusiva, buscam, por "tentativa e erro" atender alunos com deficiência e/ou NEE em suas salas de aula. O P13 complementa esta questão se referindo a como lidou com um aluno com deficiência e/ou NEE:

\begin{abstract}
Então, a forma como eu tive de trabalhar com esse aluno foi assim, dedicar um pouco mais de tempo a ele individualmente aqui na minha sala. Dentro da sala de aula é difícil, é difícil porque você tem aquele conteúdo a ser trabalhado, Ele demandava uma velocidade, de exposição que se eu fosse trabalhar naquela velocidade, dentro da sala de aula nos dias de aula normal, eu não teria coberto $50 \%$ da ementa disciplina, tinha bastante dificuldade mesmo (P13).
\end{abstract}

Para Zabalza (2004) e Cunha (2014) o professor de ensino superior além de precisar ter uma formação aprofundada do conteúdo disciplinar pelo qual é responsável, precisa também focar no saber pedagógico. As atividades de ensino não são mera reprodução das pesquisas desenvolvidas ou estudadas pelos docentes, elas exigem conhecimentos teóricos e práticos vinculados à área educacional.

A formação de professores constitui-se como um dos requisitos fundamentais para que as condições necessárias ao processo inclusivo se tornem realidade, não se restringindo apenas à aceitação de alunos com deficiência e/ou NEE em ambiente escolar, mas sim sua efetiva participação. Nesse sentido, os formadores afirmam a necessidade de formação específica, mas também destacam que estes argumentos sobre "não tive formação" devem ser repensados e não podem servir como justificativas para se ausentarem ou se omitirem neste processo. A seguir destacamos a fala de P5 a respeito das experiência na educação básica que provoca reflexões também para o ensino superior:

Então, é uma questão dialética... Porque eu não posso afirmar que não fez falta. Pensando hoje, inclusive, como eu tenho trabalhado a compreensão sobre a docência e aprendizagem da docência, a gente sabe que a formação inicial é um lugar que vai te formar para você começar a ensinar, a exercer a profissão. Então a formação continuada é muito importante. Mas, óbvio, que se você tiver, desde a formação inicial uma dedicação e também não é só uma disciplina; mas é ter espaços formativos na formação inicial acho que seria fundamental. Eu não tive. [...] E a fala de nós (corpo docente) eu estava ali como coordenador do médio, mas eu era professor também; e vários de nós falando: "eu não tive oportunidade, não fui formado para isso, não tive isso na minha formação..." É engraçado essa fala porque, na verdade, a gente tem um monte de coisa na formação. Mas, o que me chamou muito a atenção foi o que a mãe disse... isso me marcou muito... até hoje eu falo dessa forma com os alunos aqui, na graduação. A mãe disse: 'eu também não tive formação. Só que ele veio. E eu tive que aprender a lidar com ele'. A partir 
desse momento foi emocionante, a gente ficou muito mexido. E ao mesmo tempo: é isso minha gente, vamos lá, vamos aprender, vamos estudar. (P5).

Ainda relatando as vivências com alunos com deficiência e/ou NEE alguns docentes evidenciaram situações positivas, tais como:

\begin{abstract}
Eu já ministrei disciplina para aluno com necessidades especiais, não aqui na Unifal, em uma outra instituição que eu fui professor... Desculpa, nessa instituição eram dois alunos, um era cego, completamente, e o outro era uma aluna que não falava, não escutava e não falava, surda e muda. Então, eles apareceram na sala de aula e eu tive que, no primeiro momento, me organizar para ministrar disciplina para eles. Mas depois a instituição contribuiu, no caso da aluna tinha um intérprete, e do aluno que era cego, tinha um computador que fazia a leitura, toda a tradução pra ele, então foi mais fácil. (PAl8)

Na verdade depois de conhecer o E (um amigo pessoal que tem baixa visão), eu tive um aluno com baixa visão... E na verdade talvez se eu não tivesse conhecido ele (E) antes disso, eu não teria parado para pensar também na questão. (P4)

O que eu fiz foi conversar com o aluno e saber o que ele esperava, o que ele achava que era melhor para a condição dele e atender o que julgou que fosse melhor que fosse feito em termos educacionais. Ele disse que gostava de um exercício, prova oral, que o desempenho era melhor, e assim foi feito. (PAl10)
\end{abstract}

Neste sentido, Zabalza (2004) aponta uma série de dilemas que podemos encontrar na formação e práticas dos docentes, tanto no que se refere à forma como as instituições de Educação Superior encaminham a questão, quanto aos conteúdos e metodologias que podem ser adotadas para atender as necessidades de formação dos docentes. Portanto, é essencial discutirmos as práticas pedagógicas dos docentes universitários que possam favorecer a formação do licenciando para atuar em uma escola que respeite os ideais inclusivos.

Um aspecto que chamou a atenção na fala de um docente, retrata atitudes que dificultam o processo inclusivo com a presença de barreiras atitudinais, muitas vezes expressas de forma preconceituosa, mas que quando superadas oferecem potenciais que precisam ser explorados:

\begin{abstract}
Na universidade eu nunca tinha pego outro problema de deficiência mesmo, nem auditiva nem visual, mas há alguns anos atrás eu peguei um aluno com um grau de dislexia muito grave aqui na Biologia, ninguém tinha preparo para acompanhar ele, foi uma situação muito delicada porque eu peguei esse menino no segundo período de curso na época e ele já tinha reprovado em todas as disciplinas do primeiro, ele já era visto como mau aluno. [...] Na minha primeira prova eu fiquei indignada com a nota dele, fui conversar com meu esposo que já tinha dado aula anteriormente, ele já tinha um preconceito muito ruim com esse menino, dizia que ele não estava nem aí, que não estudava, todo mundo reclamava. Aí eu fui entender conversando com ele, descobri que ele já tinha dislexia detectada, que ele tentou entrar com regime especial na universidade, e não foi feito nada por ele na época, disseram que aqui não tinha estrutura para isso. Eu entrei com pedido no colegiado do curso para que as provas dele fossem orais, $e$ esse menino passou, formou, ele fez o TCC comigo. (PAl9).
\end{abstract}

As barreiras atitudinais, físicas e o déficit na formação docente são questões que podem levar ao processo de inclusão marginal, que transformam as escolas e universidades em ambientes perversos, degradantes e que às vezes não possibilitam a participação efetiva no processo de ensino-aprendizagem. Vale destacar que não estamos desconsiderando os grandes 
desafios presentes na formação de professores e na prática docente, entretanto, estes desafios não nos exime da responsabilidade de ensinar a todos os nossos alunos, indistintamente.

\section{2 Incentivo da universidade para a formação dos formadores voltada para a educação inclusiva}

Ao retratarem suas experiências os docentes indicam a necessidade de apoio institucional para a realização do processo inclusivo. Podemos destacar alguns exemplos que os informantes relataram sobre a importância em ter conhecimento e participar destas iniciativas:

Eu não vou falar que eu tive um incentivo, mas que existe... Eu sei que existem pessoas aqui na instituição que trabalham com o tema, tem o Núcleo de Acessibilidade também, então conhecimento de que tem pessoas e setores que fazem trabalho em relação a isso aqui dentro da instituição, sim, eu tenho. Agora que eu já os procurei pra me informar mais, isso não... (PAl8).

A gente tem aqui na Unifal [...] cursos que são oferecidos para os docentes e para os técnicos. Se não me engano, nesse semestre vai ser oferecido um curso, então a gente tem sim. Se não me engano é um professor do Núcleo de Acessibilidade, então a gente tem esses recursos aqui, não sei se isso é o suficiente, mas a gente tem. (PAl13)

Notamos que os docentes da UNIFAL destacam ter conhecimento de algum incentivo ou ação por parte da instituição ou, ao menos, de pessoas envolvidas com a temática. Apenas um docente relatou um aspecto contrário.

Já os docentes da UFSCar relataram que sentem a necessidade de incentivo por parte da instituição, apontando apenas algumas atitudes isoladas, quando acontecem. Por exemplo:

\footnotetext{
Eu não vou lembrar agora, mas eu acho que foi em 2013, que eles solicitaram que os professores que estavam ingressando na universidade, fizesse como se fosse... era um curso online, eu não lembro o nome disso agora...em alguns momentos, vinha um pouco essa discussão da educação inclusiva, mas muito mais voltada para a diversidade (cultural) de alunos, do que para necessidades especiais. (P10).

Eu acredito que não. Isso é uma coisa que às vezes a gente discute com colegas, mas na minha opinião é pessoal é que nós não temos orientação alguma. Não, não existe, não existe nenhuma orientação, por exemplo, digamos que eu recebesse um aluno com deficiência visual, o que o que a Universidade sugere que eu faça?. [...] Só para reafirmar um pouco, eu acho que realmente sinto falta da Universidade formalizar, mais procedimentos, vislumbrando a questão de alunos com necessidades especiais, acho que é mais nesse ponto que eu acho que tá faltando, na minha opinião, alguma coisa importante (P2).
}

São questões que, às vezes, parecem contraditórias pois os docentes demonstram ciência sobre a necessidade de formação para a educação inclusiva, no entanto, também relatam a necessidade da obrigatoriedade para tal formação, vinculando, em alguns casos, à presença de um aluno com alguma NEE e/ou deficiência para que o processo formativo se inicie. Ou como apontado pelos informantes P14: “é necessário colocar isso em um plano de valorização da 
carreira, porque se não, serão poucos os professores que irão atrás" e PA112: "para que um docente faça isso tem que querer fazer, tem que sentir essa necessidade. Se existisse uma política que a participação em determinadas discussões implicassem em progressão de carreira, por exemplo, tem chance do professor fazer" que assim como P10 não entendem sua responsabilidade como formador de futuros professores e indicam a necessidade de uma plano de carreira para adesão em um curso de formação sobre a temática.

Nesse sentido, cabe ressaltar a importância de dois objetivos que esta pesquisa trata diretamente, ou seja, identificar e analisar o entendimento que os docentes universitários possuem acerca do processo inclusivo, e as práticas inclusivas desenvolvidas pelos mesmos que se vinculem à formação dos licenciandos. Estes, são aspectos fundamentais para ampliar a discussão sobre a formação de professores no contexto do processo inclusivo.

No Brasil, o conceito de inclusão vem sendo enfatizado nas políticas educacionais e nos documentos norteadores da educação, principalmente da Educação Especial. No entanto, são documentos restritos ao conhecimento de apenas alguns docentes. Ainda é preciso avançar muito no entendimento de que o aluno com deficiência e/ou NEE é de responsabilidade de todos. E para isso as instituições precisam se posicionar oficialmente, envolvendo o corpo docente no processo de formação continuada dos formadores para que seja efetiva a formação inicial dos futuros professores, que atuarão na educação básica inclusiva.

Os docentes participantes nos ajudaram com sugestões para isso, conforme será discutido a seguir.

\section{3 Sugestões para melhoria da formação dos formadores em relação à inclusão}

Os docentes participantes deste estudo demonstraram a necessidade de discussões e aproximações para os processos formativos, seja de modo institucional ou entre pares, como no exemplo:

Eu acho que a primeira coisa que eu acho que faz falta, o que eu sinto um pouco de falta é a troca de experiências, a gente ter algum momento que a gente possa trazer isso. [...] Outras pessoas que trabalham nessa área trocar informação, a gente ter um núcleo de trabalho para isso. Outra coisa que eu sinto falta por exemplo, eи faço um evento, no meu caso que vou trazer questões da surdez, palestras, não vai nenhum Professor, ninguém participa, lógico que horário pode ser de aula, mas a gente tem que tomar um pouco de cuidado de divulgar, de tentar ver tentar combinar, mas eu faço feiras, faço as apresentações, mas eu percebo que são pouquíssimos professores que vão contemplar, então seria uma questão em que está aqui na universidade e as coisas estão acontecendo aqui e isso está passando, as pessoas poderiam aproveitar e ter benfeitorias com isso, para conhecer sobre; acho que é um ponto quando a gente puder ter, de alguma forma uma convivência que a gente pudesse colocar essas coisas, para se fortalecer dentro da Universidade para a gente aqui dentro do CCA, se fortalecer como um grupo que trabalha com as coisas do tipo e a gente fazer coisas, porque acaba sempre ficando projetos muitos separados, coisas que a gente nem fica sabendo (P24). 
Também demonstraram preocupações com as condições de trabalho, justificando a "falta de tempo" para isso; poderíamos discutir a questão das prioridades e exigências para a função docente como, por exemplo, a valorização da pesquisa em detrimento às atividades de ensino, tal como relatado por PAl13:

Acho que o que faltaria é o tempo para esse professor poder se dedicar a estudar mais, mas isso não é só em relação a inclusão, acho que em geral. [...] Acho que o que tem de iniciativa na universidade é interessante, eu por exemplo, não vou poder fazer esse curso porque não tenho tempo para ir lá, então acho que o que falta na verdade é condição de trabalho (PAll3).

Embora o docente não tenha se referido explicitamente sobre as questões de pesquisa, sabemos da demanda e cobranças que os professores universitários têm em relação a isso. A cultura universitária atribui maior status acadêmico às atividades de pesquisa, até "transformálas no componente básico da identidade e do reconhecimento do docente universitário" (ZABALZA, 2004, p. 154).

Zabalza (2004) discute que é comum que nos concursos de seleção para ingresso nas instituições de Ensino Superior, a capacidade de pesquisa tem peso muito maior do que as atividades de docência. Este ponto enfatiza ainda mais a cisão entre o tripé no qual a universidade está pautada - ensino, pesquisa e extensão - levando a docência para um lugar marginal no status universitário. Claramente as atividades de pesquisa e de docência exigem habilidades distintas, mas concordamos com o autor de que a justificativa que para ser um bom professor universitário é preciso ser um bom pesquisador, pois para pesquisar é necessário um nível de desenvolvimento intelectual superior e não evita que os concursados muitas vezes atuem de forma ineficiente em sala de aula.

Esta tensão entre docência e pesquisa convive com outra nos cursos de licenciatura, àquela estabelecida entre as disciplinas entendidas como específicas e as pedagógicas. Tendo em vista que os docentes universitários, na maior parte das vezes, não possuem em sua formação nos cursos de mestrado e doutorado espaços que se voltem para os conhecimentos pedagógicos, em especial àqueles sobre o desenvolvimento e aprendizagem de alunos com NEE e/ou deficiência, a formação dos formadores acaba por se fragmentar entre aqueles que ensinam o conhecimento disciplinar vinculado ao curso de escolha do licenciando, e aqueles que ensinam o conhecimento pedagógico. Apesar de podermos fazer uma longa discussão, que não cabe a este artigo, sobre quais são as disciplinas específicas nos cursos de licenciatura, afinal estamos falando em graduações que objetivam a formação de professores e não de Químicos, Físicos, Matemáticos, Geógrafos, etc., para atuar fora da área pedagógica. 
A partir da análise deste núcleo, destacamos a preocupação com a adesão em cursos voltados para os formadores sobre a educação inclusiva, a necessidade de informações que possam orientar o professor caso ele tenha em sala de aula um aluno com deficiência e/ou NEE; e também e o desconhecimento ou inexistência dos mecanismos na universidade para apoiar os mesmos.

\section{4 Formação voltada para a educação inclusiva durante a trajetória acadêmica}

Para iniciar a discussão deste núcleo destacaremos respostas significativas para a análise:

Não, porque a área que eu segui não foi essa. Bom, foi área de Educação, mas de pesquisa mesmo em Bioquímica, então não se tem essas disciplinas, mesmo na pós-graduação (PAll0).

Eu ainda não tive a oportunidade de trabalhar com alguém que tivesse algum tipo de deficiência para eu ter que aplicar a questão da Educação Inclusiva, mas é essencial, porque mais cedo ou mais tarde a gente vai ter esse tipo de contato e a gente vai precisar dessas informações e as informações que eu tenho são superficiais, então se eu chegasse em uma sala de aula e tivesse algum aluno com alguma necessidade especial eu teria que procurar e estudar sobre aquilo para poder dar uma aula significativa para o aluno (PAll1).

A partir do corpus de dados da pesquisa, notamos que apenas três informantes afirmaram ter formação voltada para a área de educação especial e/ou inclusiva, sendo que o P24 atua como professor nesta área, o PA119 teve sua experiência formativa nos anos posteriores a sua graduação, e o PA113 teve contato com estas questões durante a graduação, mas não considerou este contato significativo.

Os 15 outros informantes relataram não ter nenhum tipo de formação voltada para esta área durante sua trajetória acadêmica, entretanto 11 deles relataram alguma questão pessoal ou educacional que possuía relação com a área. Inicialmente é interessante destacar que ao serem questionados sobre sua formação, estes 11 docentes de alguma forma puderam relatar experiência ou opiniões sobre a questão, sendo que 3 deles deixaram claro em sua resposta que é um conhecimento que faz falta para sua atuação como docente.

Outro fator interessante é que o P4 afirmou que foi o contato pessoal que teve com um aluno com deficiência visual durante o seu mestrado que o fez ter interesse na área de ensino de física para alunos com esta deficiência, e hoje desenvolve pesquisas sobre o assunto. Também o P5 e o P14 trouxeram relatos de aproximação com a temática da inclusão a partir de contatos pessoais ocorridos durante a pós-graduação dos mesmos.

O que fica evidente neste núcleo é que a maioria dos docentes de alguma forma já pensou sobre o assunto, pelo menos de maneira superficial, o que demonstra certa sensibilidade para a questão. Porém, precisamos discutir, por exemplo, a resposta do PA110, já que ele diz 
que não possui formação sobre a inclusão, pois voltou-se para a área de Bioquímica. Esta afirmação é preocupante, pois independente da área na qual pesquisa, o docente ministra disciplinas em cursos de licenciatura, sendo assim essencial que ele entenda o seu papel e responsabilidade como formador de professores.

Esta cisão entre a área específica e pedagógica, assim como discutido por Gatti, Barreto e André (2011) e Saviani (2009) está vinculada ao modelo “3+1", que foi predominante nos cursos de licenciatura durante parte do século XX e ainda se faz presente nos cursos atuais.

Gatti (2010) ao levar em consideração os apontamentos de Tardif e Lessard (2005) aponta que a docência não pode ser interpretada como ocupação secundária, já que constitui um setor de grande importância na sociedade atual, que pode contribuir para entender as transformações nela ocorridas.

\begin{abstract}
No que concerne à formação de professores, é necessária uma verdadeira revolução nas estruturas institucionais formativas e nos currículos da formação. As emendas já são muitas. A fragmentação formativa é clara. É preciso integrar essa formação em currículos articulados e voltados a esse objetivo precípuo. A formação de professores não pode ser pensada a partir das ciências e seus diversos campos disciplinares, como adendo destas áreas, mas a partir da função social própria à escolarização - ensinar às novas gerações o conhecimento acumulado e consolidar valores e práticas coerentes com nossa vida civil (GATTI, 2010, p. 1375).
\end{abstract}

Desta forma, destaca-se a forte tradição disciplinar que marca a formação docente e orienta os futuros professores opondo-se as tentativas de caráter interdisciplinar para a constituição do currículo de cursos de licenciatura.

Esta tradição disciplinar e fragmentação presente nestes cursos fica clara no posicionamento do docente PAl10, já que o mesmo justifica seu distanciamento da temática por sua formação em uma área que dentro das licenciaturas é considerado como saber específico, portanto com a falsa ideia de que os professores destas disciplinas não precisam se preocupar com a formação dos futuros professores para atuar na educação básica inclusiva.

Outro aspecto que precisamos analisar, a partir dos dados deste estudo, é que se torna alarmante que 15 dos 18 docentes não tenham formação pertinente a área de educação inclusiva, já que todos atuam em cursos de licenciatura. Segundo Gatti, Barreto e André (2011) um dos pontos marcantes de nossa sociedade é a afirmação do direito à diferença por diversos setores sociais, trazendo consequências para a educação tanto em sua prática quanto na organização curricular, impactando assim a formação docente.

Os desafios candentes que são colocados ao governo da educação e às suas políticas, em particular às questões da formação de docentes e de seu trabalho, têm-se originado dos desconfortos anunciados por diferentes grupos sociais, em diferentes condições que expõem suas necessidades e demandas e geram suas reivindicações expressas por 
vários meios (associações diversas, mídias, movimentos por mais e melhor educação, etc.). Esses desconfortos relacionam-se a novas posturas ante as injustiças sociais, marcadamente as injustiças de status social, que estão relacionadas com a ordem cultural em nossa sociedade, aliada às possibilidades de sobrevivência digna (GATTI; BARRETO; ANDRÉ, 2011, p. 24-25).

Sendo assim, consideramos que a educação tem papel primordial e o ideal de educação inclusiva é consoante à busca de igualdade de direitos, tanto no que se refere à escolarização quanto à participação social. A busca pela construção de uma escola democrática, na qual as diferenças humanas sejam respeitadas e as necessidades educacionais especiais atendidas podem ser vista como meta, sendo a educação inclusiva um momento de transição para a justiça social e educacional. Para tanto, a formação de professores que leve em conta estes princípios é essencial nesta busca e a preocupação com a formação destes formadores e suas práticas deve, a nosso ver, ser um foco importante de investigações. Este fator ganha destaque principalmente ao levarmos em consideração estudos internacionais como o de Vaillant (2006) que aponta a heterogeneidade das instituições nas quais os professores da educação básica são formados na América Latina.

\section{5 Interesse em que a instituição oportunize espaços para a formação na área de educação inclusiva para os formadores}

Constatamos que em oito das 18 entrevistas foi relatada a questão do interesse em participar de espaços formativos voltados para à educação inclusiva (P2, P4, P5, P13, P14, P20, PA118 e PAl19). Estes professores afirmam que gostariam que a universidade desse oportunidade de formação nesta área, neste sentido a resposta de P4 se destaca ao relatar:

[...] É complicado falar do jeito que eu vou falar. Mas é fato. Assim, se não aparecer um aluno cego
dentro da sala de aula, talvez a gente tenha colegas que nunca tenham pensado na questão. Então eu
acho que isso não poderia acontecer. [...] E também se não fosse dentro da instituição [...] algumas
propostas que acabam aparecendo isoladas [...]. Se não fossem esses casos isolados, que se fossem
iniciativas dos próprios professores isso passaria despercebido na grande maioria dos cursos de
licenciatura. Eles seriam abordados como tópicos. Eles seriam, eles iriam falar que a gente tem uma Lei
de inclusão de 2015. Mas eu duvido que iriam ler a Lei, ou que iriam estudar. Eu acredito que não. Então,
são iniciativas isoladas que acontecem. E não poderia ser. Ela teria que ser institucional (P4). É importante salientar que em algumas das entrevistas dos informantes supracitados fica clara a ideia de buscar preparação quando um aluno com deficiência e/ou NEE se matricular em uma disciplina ministrada pelo informante, entretanto, questionamos este posicionamento, pois as barreiras para a inclusão são muitas, incluindo defasagem na formação docente e barreiras atitudinais, como discutido por Amaral (2002). Será que a busca por uma formação 
“emergencial”, afinal o semestre já estará em curso e o aluno em sua sala de aula, consegue proporcionar atitudes significativas no processo de ensino aprendizagem?

Outra resposta que traz componente a ser discutido é a de P2, quando o mesmo afirma, ao ser perguntado se gostaria que a instituição fornecesse oportunidades para formação na área de educação inclusiva:

Eu acho que sim [...] é claro que todo mundo tem a sua carga de trabalho já bem, bem preenchida né, bem comprometida né. Mas o que eu quero aproveitar o aspecto universal aí né da Universidade, profissionais que trabalhem com essas áreas, encabeçar as comissões para fazer isso acontecer (P2).

Esta resposta foge um pouco à questão formativa, já que atribui aos professores que tem formação na área que conduzam comissões. Claramente espera-se que estes professores assumam papeis educacionais e administrativos no que se refere à inclusão de alunos com deficiência e/ou NEE, entretanto, não estamos aqui centrando este tipo de ação. Buscamos entender a disponibilidade dos docentes em participar de momentos formativos que possam favorecer a sua atuação com estes alunos. Apesar do participante achar que gostaria, o desvio da resposta parece-nos mostrar o pouco contato que o corpo docente tem com estas necessidades.

Por fim, destacamos a resposta de $\mathrm{P} 4$ que vai ao encontro de nosso entendimento de que a formação deve ser algo promovido de maneira contínua e não para sanar casos específicos, quando eles aparecerem: "Eu acho que sim. Porque ainda não tivemos estudantes... Aqui não. Mas, a gente não precisa também esperar ter para aprender" (P4).

Zabalza (2004) ao tratar da formação dos docentes universitários ocorre em grande parte nos cursos de pós-graduação stricto senso, sendo aí disponibilizadas oportunidades para o desenvolvimento das habilidades necessárias para conduzir um estudo investigativo. Ao contrário, a formação para a docência ocorre de forma muito mais irregular e muitas vezes individual, não havendo um locus próprio e preparação específica para tal.

Com base nestas considerações, entendemos ser essencial que a instituição ofereça oportunidades formativas, tanto na área educacional em geral, quanto no tocante ao processo inclusivo.

\section{Algumas considerações}

Como apontado anteriormente, esta investigação buscou analisar a formação dos docentes universitários para atuar com base nos pressupostos inclusivos, bem como as práticas 
desenvolvidas por eles nos cursos de licenciatura que podem favorecer a formação dos futuros professores para atuar em uma escola inclusiva e democrática.

Os dados obtidos permitiram diagnosticar que as ações pedagógicas desenvolvidas pelos docentes universitários na formação do licenciando para atuar em uma escola devem respeitar os ideais inclusivos. Verificamos que a abordagem deste processo na educação superior demanda um aprofundamento nas discussões a respeito da formação de professores; no sentido de estabelecer uma reflexão não somente sobre a prática docente, mas também uma reflexão profunda a respeito das compreensões sobre a diversidade humana e sobre pressupostos inclusivos.

Constatamos que as barreiras atitudinais, físicas e o déficit na formação docente são questões que podem levar ao processo de inclusão marginal, que transformam as escolas e universidades em ambientes perversos, degradantes e que às vezes não possibilitam a participação efetiva no processo de ensino-aprendizagem.

Verificamos, ainda, que é preciso avançar muito no entendimento de que o aluno com deficiência e/ou NEE é de responsabilidade de todos. E para isso as instituições precisam se posicionar oficialmente, envolvendo o corpo docente no processo de formação continuada dos formadores para que seja efetiva a formação inicial dos futuros professores, que atuarão na educação básica inclusiva.

O estudo permitiu evidenciar que o ideal da educação inclusiva é consoante à busca de igualdade de direitos, tanto no que se refere à escolarização quanto à participação social. Entendemos ser essencial que a instituição ofereça oportunidades formativas, tanto na área educacional em geral, quanto no tocante ao processo inclusivo.

A análise dos dados revelou preocupação com a adesão em cursos voltados para os formadores sobre a educação inclusiva, bem como a necessidade de canais que possam orientar o professor caso ele tenha em sala de aula um aluno com deficiência e/ou NEE. O desconhecimento ou inexistência dos mecanismos de apoio na universidade é algo que aflige os professores.

As constatações apresentadas pelos professores das duas instituições são semelhantes no que se refere às origens das discussões sobre a inclusão trazidas pelos estudantes; sendo elas oriundas de situações vivenciadas, especialmente, na disciplina Estágio. E ainda, a análise de dados identificou que a maior parte dos professores considera que os cursos de licenciatura das suas instituições não oportunizam uma formação adequada aos futuros professores para atuar de forma inclusiva. 
Neste sentido, entendemos que a contribuição deste estudo poderá subsidiar novas atuações nos espaços envolvidos, tendo em vista a construção de condições para o fortalecimento da escola inclusiva e do atendimento aos alunos com NEE.

\section{Agradecimento}

Agradecimentos: à FAPESP (Processo no. 2015/21617-1) e ao CNPQ (Processo no. $400128 / 2016-0$

\section{Referências}

AMARAL, Lígia. Assumpção. Diferenças, estigma e preconceito: O desafio da inclusão. In: OLIVEIRA, M. K.; SOUZA, D. T. R.; REGO, T. C. (orgs.). Psicologia, educação e as temáticas da vida contemporânea. São Paulo: Moderna, 2002. p. 233-248.

ARCE, Alessandra. Compre o kit neoliberal para a educação infantil e ganhe grátis os dez passos para se tornar um professor reflexivo. Educ. Soc., Campinas, v. 22, n. 74, p. 251-283, 2001.

BRASIL Ministério da Educação (MEC). Secretaria de Educação Fundamental. Diretrizes Curriculares Nacionais para o Ensino Especial. Resolução CNE 02. Brasília: MEC/SEF, 2001.

BRASIL. Decreto 7.611 de 17 de novembro de 2011. Disponível em:

http://www.planalto.gov.br/ccivil_03/_ato2011-2014/2011/decreto/d7611.htm. Acesso em: 10 jan. 2017.

BEZERRA, Giovani Ferreira. A inclusão escolar de alunos com deficiência: uma leitura baseada em Pierre Bourdieu. Revista Brasileira de Educação, Rio de Janeiro, v. 22, n. 69 , abr./jun. 2017. Disponível em: https://www.scielo.br/pdf/rbedu/v22n69/1413-2478-rbedu-2269-0475.pdf. Acesso em: 17 abr. de 2018.

BUENO, José Geraldo Silveira. As políticas de inclusão escolar: uma prerrogativa da educação especial? In: BUENO, J. G. S.; MENDES, G. M. L.; SANTOS, R. A. Deficiência e escolarização: novas perspectivas de análise. Araraquara, SP: Junqueira e Marin; Brasília, DF: CAPES, 2008. p. 43-63.

CUNHA, Maria Isabel da. Estratégias institucionais para o desenvolvimento profissional docente e as assessorias pedagógicas universitárias: memórias, experiências, desafios e possibilidades. Araraquara: Junqueira \& Marin, 2014.

FALKENBACH, Atos Prinz et al. A inclusão de crianças com necessidades especiais nas aulas de Educação Física na educação infantil. Movimento, Porto Alegre, v. 13, n. 2, p.37-53, maio/ago. 2007. 
FERRARI, Marian A. L. D.; SEKKEL. Marie Claire. Educação inclusiva no ensino superior: um novo desafio. Psicologia Ciência e Profissão, Brasília, 2007, v. 27, n. 4, p. 636-647, 2007. Disponível em https://www.scielo.br/pdf/pcp/v27n4/v27n4a06.pdf. Acesso em: 17 abr. de 2018.

GATTI, Bernadete Angelina Formação de professores no Brasil: características e problemas. Educação e Sociedade, Campinas, v. 31, n. 113, p. 1355-1379, 2010. Disponível em: https://www.scielo.br/pdf/es/v31n113/16.pdf?origin=publication_detail. Acesso em: 17 jun. 2020.

GATTI, Bernadete Angelina; BARRETTO, Elba Siqueira de Sá; ANDRÉ, Marli Elzira Dalmazo. Políticas docentes no Brasil. Um estado da arte. Brasília: UNESCO, 2011.

GOESSLER, Danieli de Cássia Barreto. Inclusão no ensino superior: o que revelam os microdados do censo da educação superior no período 2009-2012. In: ANPED SUL, Reunião Científica Regional da ANPED, 10., 2014, Florianópolis. Publicações do Seminário de Pesquisa em Educação da Região Sul. Reunião Científica Regional da ANPED. Florianópolis: UDESC, 2014. p. 1-16. Disponível em: http://xanpedsul.faed.udesc.br/arq_pdf/792-0.pdf. Acesso em: 18 abr. 2018.

GONZALEZ REY, Fernando Luis. Pesquisa qualitativa em psicologia: caminhos e desafios. São Paulo: Thomson, 2002.

KASSAR, Mônica de Carvalho Magalhães. Educação especial no Brasil: desigualdades e desafios no reconhecimento da diversidade. Educ. Soc., Campinas, v. 33, n. 120, p. 833-849, jul./set. 2012.

LAPLANE, Adriana. Uma análise das condições para a implementação de políticas de educação inclusiva no Brasil e na Inglaterra. Educ. Soc., Campinas, v. 27, n. 96, p. 689-715, out. 2006.

LIBÂNEO, José Carlos; OLIVEIRA, João Ferreira de Oliveira.; TOSCHI, Mirza Seabra Educação escolar: políticas, estrutura e organização. São Paulo: Cortez, 2012.

LÜDKE, Menga; ANDRÉ, Marli Eliza Dalmazo Afonso de. Pesquisa em educação: abordagens qualitativas. São Paulo: EPU, 1986.

MARTINS, José de Souza. A sociedade vista do abismo: novos estudos sobre exclusão, pobreza e classes sociais. 2. ed. Petrópolis: Vozes, 2002.

MENDES, Enicéia Gonçalves. Breve histórico da educação especial no Brasil. Revista Educación y Pedagogía, Medellín, v. 22, n. 57, mayo/ago. 2010. Disponível em: https://revistas.udea.edu.co/index.php/revistaeyp/issue/view/767. Acesso em: 17 abr. 2018.

MICHELS, Maria Helena. Práticas de ambiguidades estruturais e a reiteração do modelo médico-psicológico: A formação de professores de educação especial na UFSC. In: BUENO, J. G. S.; MENDES, G. M. L.; SANTOS, R. A. Deficiência e escolarização: novas perspectivas de análise. Araraquara: Junqueira e Marin; Brasilia: CAPES, 2008. p. 205-247. 
MURA, Antonello; ZURRU, Antioco Luigi. Inclusão escolar: a perspectiva italiana analisada em estudo sobre a percepção de professores. Currículo sem Fronteiras, Porto Alegre, v. 16, n. 2, p. 364-375, maio/ago. 2016. Disponível em:

http://www.curriculosemfronteiras.org/vol16iss2articles/mura-zurru.pdf. Acesso em: 18 abr. 2018.

PATTO, Maria Helena de Souza. Políticas atuais de inclusão escolar: Reflexão a partir de um recorte conceitual. In: BUENO, J. G. S.; MENDES, G. M. L.; SANTOS, R. A. Deficiência e escolarização: novas perspectivas de análise. Araraquara: Junqueira e Marin; Brasilia:

CAPES, 2008. p. 25-42.

PIECZKOWSKI, Tania Mara Zancanaro. Avaliação da aprendizagem de estudantes com deficiência na educação superior. Rev. bras. estud. pedagog., Brasília, v. 97, n. 247, p. 583601, set./dez. 2016. Disponível em: https://www.scielo.br/pdf/rbeped/v97n247/2176-6681rbeped-97-247-00583.pdf. Acesso em: 17 abr. 2018

PRIETRO, Rosângela Gavioli. Formação de professores para o atendimento de alunos com necessidades educacionais especiais: diretrizes nacionais para a educação básica e a educação especial. In: SILVA, S.; VIZIM, M. (orgs.). Políticas públicas: educação, tecnologias e pessoas com deficiência. Campinas: Mercado de Letras: Associação de Leitura do Brasil, 2003. p. 125-151.

SAVIANI, Dermeval. Pedagogia histórico-crítica. 10. ed. Campinas: Autores Associados, 2008.

SAVIANI, Dermeval. Escola e democracia. Campinas: Autores Associados, 2009.

TARDIF, Maurice; LESSARD, Claude. O trabalho docente: elementos para uma teoria da docência como profissão de interações humanas. Petrópolis: Vozes, 2005.

VAILLANT, Denise. Atraer y retener buenos profesionales en la profesión docente: políticas en Lationoamérica. Revista Educación, Madrid, p. 117-140, maio/ago, 2006.

VYGOTSKI, Lev Semiónovic. Obras Escogidas V. Fundamentos de defectología. Madrid: Visor, 1997.

ZABALZA, Miguel Angel. O ensino universitário: seu cenário e seus protagonistas. Porto Alegre: Artmed, 2004. 